\title{
A Food-Grade, Secretory Expression of IL1RA Protein in a Lactococcus Lactis System for Potential Oral Therapy on IBD
}

\author{
Jin $\mathrm{CHENG}^{1}$, Jin $C A \mathrm{O}^{1}$, Jia $C A O^{1}$, Xiao-feng $\mathrm{WANG}^{1}$ and Yan-ru \\ $\mathrm{GE}^{1, \mathrm{a},{ }^{,}}$
}

${ }^{1}$ School of Pharmacy, Jiangsu University, 301\# Xuefu Road, Zhenjiang, Jiangsu, China

ageyanru@ujs.edu.cn

${ }^{*}$ Corresponding author

Keywords: Interleukin 1 receptor antagonist (IL1RA), Lactococcus lactis, Recombinant, Inflammatory bowel disease (IBD).

\begin{abstract}
Interleukin $1 \beta$ (IL1 $\beta)$ is a potential target for IBD treatment. IL1 receptor antagonist (IL1RA) can blocks the biologic activity of IL1 by competitively inhibiting IL1 binding to the IL1R, so IL1RA is suggested to have possible therapeutic applications in treatment of IBD. By using a food-grade recombinant Lactococcus lactis system, a constitutive expression vector IL1RA:pNZ8149 was constructed and transferred into a L. lactis host NZ3900 in this study. The engineered strain was fermented and detected by colonies PCR and Western blot, the results indicate that the IL1RA secretory expression can be archived by IL1RA/NZ3900.
\end{abstract}

\section{Introduction}

Interleukin 1 (IL1) plays a significant role in the regulation of immune and inflammatory responses to infections. IL1 production is induced in response to inflammatory stimuli and mediates various physiologic responses including inflammatory and immunological responses. IL1 $\beta$ is a member of IL1 family, the pro-inflammatory effect of which has been proved recent years. Research results suggest that IL1 $\beta$ contributes to chronic intestinal inflammation, such as inflammatory bowel disease (IBD). IL1 $\beta$ is secreted from intestinal tissues and macrophages isolated from patients with IBD, and IL1 $\beta$ levels correlate with disease severity $[1,2]$. Therefore, IL1 $\beta$ can be a potential target for IBD treatment $[2,9]$, the IL1 $\beta$ signaling pathway inhibition is an effective way for treatment of IBD.

The naturally occurring endogenous IL1 receptor antagonist (IL1RA), formerly called the IL-1 inhibitor, is a member of the IL1 cytokine family which binds to IL1 receptors with an affinity similar to that of IL1 $\alpha$ and IL1 $\beta$, but does not induce a signaling response [10]. Thus, IL1RA can blocks the biologic activity of IL1 by competitively inhibiting IL1 binding to the IL1R (fig. 1), which is expressed in a wide variety of tissues and organs [11]. In terms of protein similarities, IL1RA is more closely related to IL1 $\beta$ than it is to IL1 $\alpha$. IL1RA is suggested to have possible therapeutic applications in treatment of many diseases, including IBD [1, 2, 6, 12-14]. However, as a protein, the disadvantages of IL1RA are the short half-time by injection, low targeting and oral therapy inactivation. 


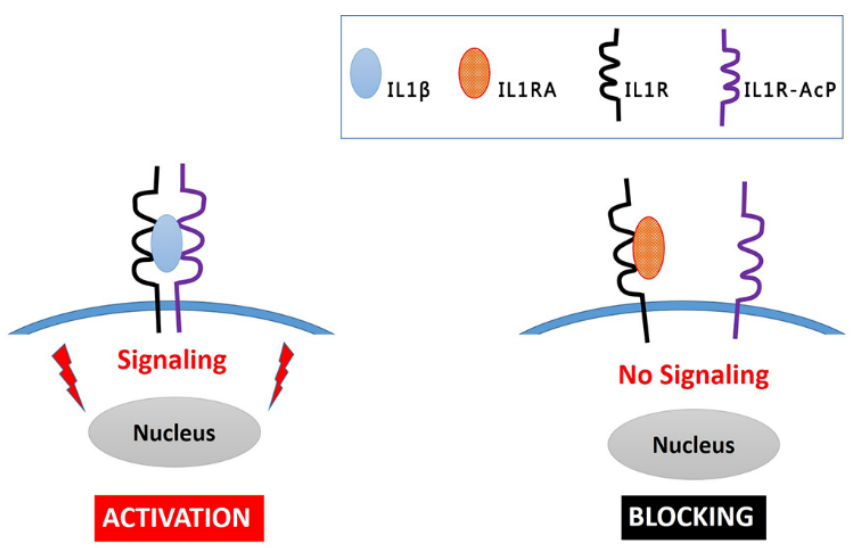

Figure 1. IL1RA working mechanism

Lactococcus lactis, as a food-grade microorganism, is widely used in the food and medicine industry [15]. Besides the natural healthy benefits, the new application for $L$. lactis is their use as the host for therapeutic protein. The species is ideal for the production of biologically useful proteins such as cytokines or peptide hormones. Because of the intestinal planting and local synthesis ability, L. lactis can delivery therapeutic molecules by viable recombinant L. lactis in situ. The successful use of food-grade L. lactis for the oral delivery of anti-inflammatory molecules to the inflamed intestine have been reported [16-18]. Besides, studies have proven that L. lactis itself can also counteract the chronic inflammatory process $[19,20]$.

In this study, a constitutive expression vector (make the host express therapeutic protein without inducer) was constructed and transferred into a L. lactis host NZ3900. The positive clone of the engineered L. lactis was selected and named IL1RA/NZ3900. The engineered strain was fermented and detected by colonies PCR and Western blot.

\section{Experimental Procedure}

According to the PUBMED database (https://www.ncbi.nlm.nih.gov/protein/), the full length of the IL1RA protein sequence is RPSGRKSSKM QAFRIWDVNQ KTFYLRNNQL VAGYLQGPNV NLEEKIDVVP IEPHALFLGIH GGKMCLSCVK SGDETRLQLE AVNITDLSEN RKQDKRFAFI RSDSGPTTSF ESAACPGWFL CTAMEADQPV SLTNMPDEGV MVTKFYFQED E. The sequence of DNA fragment encoding IL1RA has been codon optimized according to L. lactis codon usage preference. In order to make the recombinant cell secrete IL1RA to extracellular space, Usp45 signal peptide was designed at the 5' of the IL1RA DNA sequence. P2 promoter and stop codon were added at the $5^{\prime}$ and 3 ' terminal, respectively. In addition, restriction endonucleases sites NcoI and SacI were designed to insert the IL1RA fragment into the expression vector pNZ8149. The full-length gene (Fig. 2) as described above was synthesized by Biosci Biotech Co. Ltd (Hangzhou, China).



Figure 2. inserted foreign gene fragment 
A recombinant plasmid was constructed by inserting the IL1RA gene with Usp45 fragment digested with NcoI and SacI restriction enzymes, into the same restriction sites of pNZ8149. This new plasmid, named IL1RA:pNZ8149, contains a hexa-histidine tag (His6 tag) in frame with the 5' end of IL1RA gene.

The recombinant plasmid was used to transform L. lactis NZ3900 and resultant colonies were screened by Eliker selective solid culture medium and PCR. The protocol for transformation mainly followed the handbook from MoBiTec Company (Germany). In brief, the L. lactis cells were treated by ice-cold $0.5 \mathrm{M}$ sucrose and $10 \%$ glycerol solution to become competent cells. The electroporation process was as follow: $40 \mu \mathrm{l}$ cells were placed into a pre-chilled electroporation cuvette with $1 \mu \mathrm{l}$ plasmid DNA, the electroporation parameters were $2000 \mathrm{~V}, 25 \mu \mathrm{F}, 200 \Omega, 4.5-5 \mathrm{~ms}$. After that, add $1 \mathrm{ml}$ GM17-MC. keep the cuvette for $5 \mathrm{~min}$ on ice and incubate $1-1.5 \mathrm{~h}$ at $30{ }^{\circ} \mathrm{C}$. Resultant colonies were screened by Eliker selective solid culture medium. The recombinant positive clones were confirmed by colonies PCR and sequencing technique.

The recombinant NZ3900 clone was named IL1RA/NZ3900 and the protein expression was identified by western blotting. For western blotting the proteins were electroblotted onto a PVDF membrane, $1 \mathrm{~mA} / \mathrm{cm} 2$ for $1.5 \mathrm{~h}$. Proteins were reacted with a primary antibody (mouse anti-his antibody) at a dilution of 1:500 and a secondary antibody (horseradish-peroxidase conjugated goat anti mouse second $\mathrm{IgG}$ ) at a dilution of 1:5000. The target proteins on the membrane were detected by a DAB Horseradish Peroxidase Color Development Kit.

\section{Results and Discussion}

A recombinant plasmid was constructed by inserting the IL1RA gene with Usp45 fragment digested with NcoI and SacI restriction enzymes, into the same restriction sites of pNZ8149. After this step, direct sequencing and restriction enzyme reaction were performed to identify the construction. As shown in fig. 3, recombinant plasmid with the aim exogenous gene coding IL1RA was obtained.

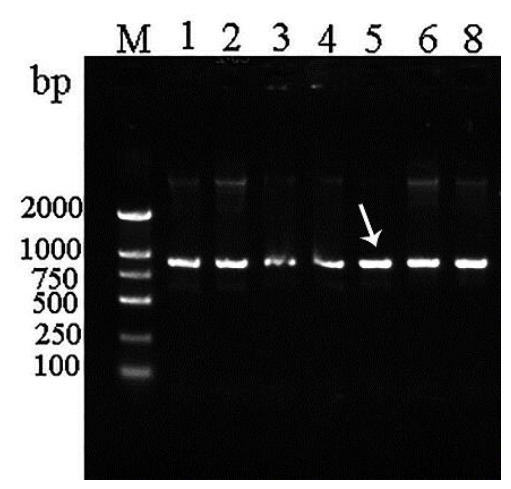

Figure 3. restriction enzyme reaction were performed to identify the construction

The recombinant NZ3900 clone was named IL1RA/NZ3900, colonies PCR was employed to detect the plasmid in the recombinant cells, as shown in fig.4-A, the IL1RA/NZ3900 contained the recombinant plasmid IL1RA:pNZ8149. The protein expression was identified by western blotting base on the hexa-histidine tag. As shown in fig.4-B, a slim bar with a molecular weight between 15 to $25 \mathrm{KDa}$ can be observed. It shows a good agreement with the theoretical value of IL1RA. 


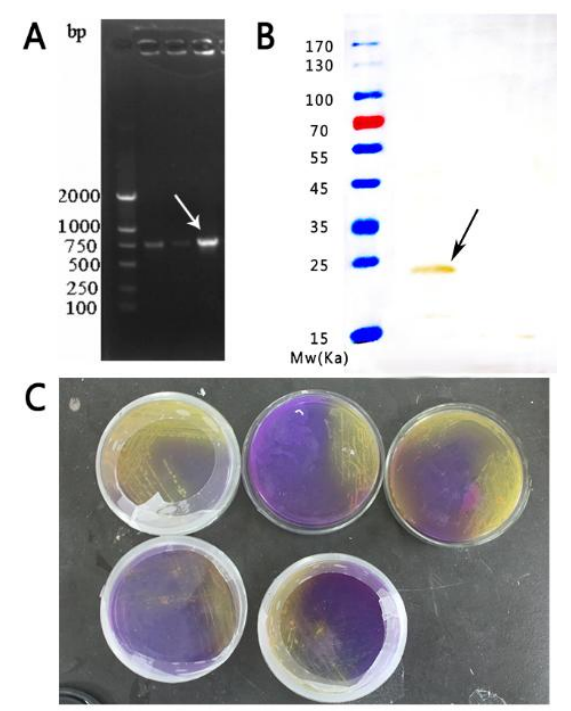

Figure 4. IL1RA/NZ3900 engineering cells construction

A. Colonies PCR; B. Western Blotting; C. amplified positive clones

To sum up, a secretory expression of IL1RA protein in a lactococcus lactis system was obtained. Because of the intestinal colonization ability and interior health-promoting of L lactis, as well as the IL1RA expressing function, the recombinant IL1RA/NZ3900 cells get the oral therapy on IBD potential. The unbalance between IL1 $\beta /$ IL1RA could be corrected by this recombinant cell stably in a long term.

\section{Conclusions}

By proper design and correct selection of recombinant expression system, a recombinant $L$. lactis which can express secretory IL1RA, named IL1RA/NZ3900 was obtained. Its colonization ability and IL1RA expression level in situ require further investigation. Through this research, the new way to treat IBD with oral IL1Ra will be explored. A significant research material was obtained for the further study on anti-inflammatory biomacromolecular drugs. The results will provide a practical way for protein oral delivery and colon site-specific delivery.

\section{Acknowledgments}

This work was supported by China Postdoctoral Science Foundation (2015M571706) and Natural Science Fund for Colleges and Universities in Jiangsu Province (16KJD350001).

\section{References}

[1] E. Voronov and R.N. Apte, IL-1 in Colon Inflammation, Colon Carcinogenesis and Invasiveness of Colon Cancer, Cancer Microenviron. 8 (2015) 187-200.

[2] E.N. Ngoh, S.B. Weisser, Y. Lo, L.K. Kozicky, R. Jen, H.K. Brugger, S.C. Menzies, K.W. McLarren, D. Nackiewicz, N. van Rooijen, K. Jacobson, J.A. Ehses, S.E. Turvey and L.M. Sly, Activity of SHIP, Which Prevents Expression of Interleukin 1beta, Is Reduced in Patients With Crohn's Disease, Gastroenterology. 150 (2016) 465-476. 
[3] M. Coccia, O.J. Harrison, C. Schiering, M.J. Asquith, B. Becher, F. Powrie and K.J. Maloy, IL-1beta mediates chronic intestinal inflammation by promoting the accumulation of IL-17A secreting innate lymphoid cells and CD4(+) Th17 cells, J. Exp. Med. 209 (2012) 1595-1609.

[4] M. Scarpa, S. Kessler, T. Sadler, G. West, C. Homer, C. McDonald, C. de la Motte, C. Fiocchi and E. Stylianou, The epithelial danger signal IL-1alpha is a potent activator of fibroblasts and reactivator of intestinal inflammation, Am. J. Pathol. 185 (2015) 1624-1637.

[5] I. Soufli, R. Toumi, H. Rafa and C. Touil-Boukoffa, Overview of cytokines and nitric oxide involvement in immuno-pathogenesis of inflammatory bowel diseases, World J Gastrointest Pharmacol Ther. 7 (2016) 353-360.

[6] D.K. Podolsky, Inflammatory bowel disease, N. Engl. J. Med. 347 (2002) 417-429.

[7] Q. Zhou, G.S. Lee, J. Brady, S. Datta, M. Katan, A. Sheikh, M.S. Martins, T.D. Bunney, B.H. Santich, S. Moir, D.B. Kuhns, D.A. Long Priel, A. Ombrello, D. Stone, M.J. Ombrello, J. Khan, J.D. Milner, D.L. Kastner and I. Aksentijevich, A hypermorphic missense mutation in PLCG2, encoding phospholipase Cgamma2, causes a dominantly inherited autoinflammatory disease with immunodeficiency, Am. J. Hum. Genet. 91 (2012) 713-720.

[8] A. Almeida de Jesus and R. Goldbach-Mansky, Monogenic autoinflammatory diseases: concept and clinical manifestations, Clin. Immunol. 147 (2013) 155-174.

[9] A.M. Bianco, M. Girardelli, D. Vozzi, S. Crovella, G. Kleiner and A. Marcuzzi, Mevalonate kinase deficiency and IBD: shared genetic background, Gut. 63 (2014) 1367-1368.

[10] B.S. Hamilton, Y. Brede and T.J. Tolbert, Expression and characterization of human glycosylated interleukin-1 receptor antagonist in Pichia pastoris, Protein Expr. Purif. 59 (2008) 64-68.

[11] C.H. Hannum, C.J. Wilcox, W.P. Arend, F.G. Joslin, D.J. Dripps, P.L. Heimdal, L.G. Armes, A. Sommer, S.P. Eisenberg and R.C. Thompson, Interleukin-1 receptor antagonist activity of a human interleukin-1 inhibitor, Nature. 343 (1990) 336-340.

[12] J. Henao-Mejia, E. Elinav, T. Strowig and R.A. Flavell, Inflammasomes: far beyond inflammation, Nat. Immunol. 13 (2012) 321-324.

[13] W.P. Arend, M. Malyak, C.J. Guthridge and C. Gabay, Interleukin-1 receptor antagonist: role in biology, Annu. Rev. Immunol. 16 (1998) 27-55.

[14] F.L. van de Veerdonk, M.G. Netea, C.A. Dinarello and J.W. van der Meer, Anakinra for the inflammatory complications of chronic granulomatous disease, Neth. J. Med. 69 (2011) 95.

[15] D.S. Pontes, M.S. de Azevedo, J.M. Chatel, P. Langella, V. Azevedo and A. Miyoshi, Lactococcus lactis as a live vector: heterologous protein production and DNA delivery systems, Protein Expr. Purif. 79 (2011) 165-175.

[16] L.G. Bermudez-Humaran, C. Aubry, J.P. Motta, C. Deraison, L. Steidler, N. Vergnolle, J.M. Chatel and P. Langella, Engineering lactococci and lactobacilli for human health, Curr. Opin. Microbiol. 16 (2013) 278-283. 
[17] S.A. Limaye, R.I. Haddad, F. Cilli, S.T. Sonis, A.D. Colevas, M.T. Brennan, K.S. $\mathrm{Hu}$ and B.A. Murphy, Phase 1b, multicenter, single blinded, placebo-controlled, sequential dose escalation study to assess the safety and tolerability of topically applied AG013 in subjects with locally advanced head and neck cancer receiving induction chemotherapy, Cancer. 119 (2013) 4268-4276.

[18] L. Steidler and P. Rottiers, Therapeutic drug delivery by genetically modified Lactococcus lactis, Ann. N. Y. Acad. Sci. 1072 (2006) 176-186.

[19] P. Veiga, C.A. Gallini, C. Beal, M. Michaud, M.L. Delaney, A. DuBois, A. Khlebnikov, J.E. van Hylckama Vlieg, S. Punit, J.N. Glickman, A. Onderdonk, L.H. Glimcher and W.S. Garrett, Bifidobacterium animalis subsp. lactis fermented milk product reduces inflammation by altering a niche for colitogenic microbes, Proc. Natl. Acad. Sci. U. S. A. 107 (2010) 18132-18137.

[20] N.P. McNulty, T. Yatsunenko, A. Hsiao, J.J. Faith, B.D. Muegge, A.L. Goodman, B. Henrissat, R. Oozeer, S. Cools-Portier, G. Gobert, C. Chervaux, D. Knights, C.A. Lozupone, R. Knight, A.E. Duncan, J.R. Bain, M.J. Muehlbauer, C.B. Newgard, A.C. Heath and J.I. Gordon, The impact of a consortium of fermented milk strains on the gut microbiome of gnotobiotic mice and monozygotic twins, Sci. Transl. Med. 3 (2011) 106 ra106. 